\title{
Comparative Effectiveness of Insulin versus Combination Sulfonylurea and Insulin: a Cohort Study of Veterans with Type 2 Diabetes
}

\author{
Jea Young Min, PharmD, MPH ${ }^{1,2}$, Marie R. Griffin, $M D, M P H^{1,2,3}$, Adriana M. Hung, MD, MPH ${ }^{1,2}$, \\ Carlos G. Grijalva, MD, MPH ${ }^{1,3}$, Robert A. Greevy, PhD ${ }^{1,4}$, Xulei Liu, MD, MS ${ }^{1,4}$, Tom Elasy, MD, MPH ${ }^{1,2}$, \\ and Christianne L. Roumie, $M D, M P H^{1,2}$
}

\begin{abstract}
'Veterans Health Administration - Tennessee Valley Healthcare System Geriatrics Research Education Clinical Center (GRECC), Health Service Research and Development Center (HSRD), Nashville, TN, USA; ${ }^{2}$ Department of Medicine, Vanderbilt University, Nashville, TN, USA; ${ }^{3}$ Department of Health Policy, Vanderbilt University, Nashville, TN, USA; ${ }^{4}$ Department of Biostatistics, Vanderbilt University, Nashville, TN, USA.
\end{abstract}

BACKGROUND: Type 2 diabetes patients often initiate treatment with a sulfonylurea and subsequently intensify their therapy with insulin. However, information on optimal treatment regimens for these patients is limited.

OBJECTIVE: To compare risk of cardiovascular disease (CVD) and hypoglycemia between sulfonylurea initiators who switch to or add insulin.

DESIGN: This was a retrospective cohort assembled using national Veterans Health Administration (VHA), Medicare, and National Death Index databases.

PARTICIPANTS: Veterans who initiated diabetes treatment with a sulfonylurea between 2001 and 2008 and intensified their regimen with insulin were followed through 2011.

MAIN MEASURES: The association between insulin versus sulfonylurea + insulin and time to CVD or hypoglycemia were evaluated using Cox proportional hazard models in a 1:1 propensity score-matched cohort. CVD included hospitalization for acute myocardial infarction or stroke, or cardiovascular mortality. Hypoglycemia included hospitalizations or emergency visits for hypoglycemia, or outpatient blood glucose measurements $<60 \mathrm{mg} / \mathrm{dL}$. Subgroups included age $<65$ and $\geq 65$ years and estimated glomerular filtration rate $\geq 60$ and $<60 \mathrm{ml} / \mathrm{min}$.

KEY FINDINGS: There were 1646 and 3728 sulfonylurea monotherapy initiators who switched to insulin monotherapy or added insulin, respectively. The 1596 propensity score-matched patients in each group had similar baseline characteristics at insulin initiation. The rate of CVD per 1000 person-years among insulin versus sulfonylurea + insulin users were 49.3 and 56.0, respectively [hazard ratio (HR) 0.85, $95 \%$ confidence interval (CI) 0.64 , 1.12]. Rates of first and recurrent hypoglycemia events per 1000 person-years were 74.0 and 100.0 among insulin users compared to 78.9 and 116.8 among sulfonylurea plus insulin users, yielding HR (95\% CI) of 0.94 (0.76,

Electronic supplementary material The online version of this article (doi:10.1007/s11606-016-3633-2) contains supplementary material, which is available to authorized users.

Received August 20, 2015

Revised January 21, 2016

Accepted February 1, 2016

Published online February 262016
$1.16)$ and $0.87(0.69,1.10)$, respectively. Subgroup analysis results were consistent with the main findings.

CONCLUSIONS: Compared to sulfonylurea users who added insulin, those who switched to insulin alone had numerically lower CVD and hypoglycemia events, but these differences in risk were not statistically significant.

KEY WORDS: diabetes mellitus; cardiovascular disease; hypoglycemia; insulin; sulfonylurea; comparative effectiveness.

J Gen Intern Med 31(6):638-46

DOI: $10.1007 / \mathrm{s} 11606-016-3633-2$

(C) Society of General Internal Medicine 2016

\section{INTRODUCTION}

The American Diabetes Association (ADA) and European Association for the Study of Diabetes (EASD) consensus statement on the management of individuals with diabetes recommends metformin as first-line treatment for type 2 diabetes. ${ }^{1}$ However, among U.S. veterans, $43 \%$ of newly diagnosed diabetes patients initiated treatment with a sulfonylurea (Roumie et al., under review). This could be due to ease of regimen initiation (no titration usually needed), providers' preference or contraindications to metformin use (e.g., patients with impaired kidney function due to concerns for lactic acidosis). $^{2-6}$

Although the optimal strategy to intensify initial sulfonylurea monotherapy remains unclear, experts have recommended that intensification may be accomplished by insulin as add-on therapy or insulin monotherapy. ${ }^{7-9}$ However, evidence comparing important clinical outcomes between these specific intensification regimens is lacking. Furthermore, there are continued concerns that insulin and sulfonylureas may increase cardiovascular disease (CVD) risk compared to metfor$\mathrm{min}$, despite their ability to effectively achieve glycemic control. ${ }^{10-13}$ In addition, both sulfonylureas and insulin cause hypoglycemia, which remains a major therapy-limiting concern of both patients and providers. ${ }^{14-16}$

In this study, our aim was to investigate the risk of several important clinical outcomes among U.S. veterans who intensified their initial sulfonylurea monotherapy by switching to 
insulin alone or adding insulin. We specifically focused on CVD as a long-term outcome and hypoglycemia as a shortterm outcome.

\section{METHODS}

\section{Study Design and Data Sources}

We assembled a retrospective cohort of Veterans Health Administration (VHA) patients who initiated treatment for type 2 diabetes. Information on these patients included dispensed medications (date filled, days supplied and pill/vial number $)^{17}$; demographics; and ICD9-CM coded diagnostic and procedure information from inpatient and outpatient encounters. ${ }^{18}$ We collected laboratory results from clinical sources. Vital signs data included all outpatient height, weight and blood pressure measurements. For enrollees in Medicare or Medicaid, we obtained enrollment, inpatient and outpatient claims files, and prescription (Part D) data from the Centers for Medicare and Medicaid Services through the VHA's interagency exchange agreement. ${ }^{19,20}$ We obtained dates of death from VHA vital status files and causes of death from National Death Index (NDI) data. ${ }^{21}$ The institutional review boards of Vanderbilt University and VHA Tennessee Valley Healthcare System approved this study.

\section{Study Population}

The study population comprised U.S. veterans aged 18 years or older who filled a new prescription for sulfonylurea monotherapy between October 2001 and September 2008; had not filled any antihyperglycemic drug in the prior 180 days; and had at least one encounter or prescription fill every 180 days during the prior 2 years. New users of sulfonylurea monotherapy were followed through September 2011 for a new insulin prescription fill, and became eligible for the treatment intensification cohort at that time (Supplemental Figure 1). Because we were interested in patients who intensified due to failing sulfonylurea monotherapy, we excluded patients who were considered non-adherent at the time insulin was prescribed. To accomplish this, we excluded patients who had no sulfonylurea supply remaining in the 180 days prior to the date of first insulin prescription, based on their prescription fill records. We also excluded patients with hospice care; dialysis or baseline estimated glomerular filtration rate $($ GFF $)<15 \mathrm{ml} / \mathrm{min}$; organ/ bone marrow transplant; and missing baseline serum creatinine at therapy intensification or in the prior 730 days.

\section{Exposures}

The two comparison groups were: patients who switched to insulin (long-acting, premixed, or short/fast-acting insulin) and patients who continued sulfonylurea (glyburide, glipizide or glimepiride) with the addition of insulin. The treatment intensification regimen was defined and follow-up began at 180 days after the first insulin prescription, to distinguish patients who continued both sulfonylurea and insulin from those who switched to insulin monotherapy. Follow-up continued until study outcome, death, loss to follow-up (no contact with VHA for $>180$ days) or study end (30 September 2011). Patients were also censored if they had a regimen change or were non-persistent on their study regimen ( 90 days with no insulin prescription fill). In a previous study, we showed that the 90-day gap definition of treatment persistence approximated $80 \%$ adherence to the regimen in our study population. ${ }^{22}$

\section{Co-Primary Outcomes: Cardiovascular Disease and Hypoglycemia}

Fatal and Nonfatal Cardiovascular Disease. The composite cardiovascular outcome was fatal and nonfatal cardiovascular events. Nonfatal events included hospitalization for acute myocardial infarction (AMI) or stroke (Supplemental Table 1). These definitions previously yielded a positive predictive value between 81 and $90 \%$ compared with review of VHA medical records. ${ }^{23}$ Fatal cardiovascular events included any death identified based on NDI death certificates with an ICD-10 coded underlying cause of death including I00-I78 (cardiovascular deaths) or R98, R99, R960, R961 (unattended deaths), excluding I30.X (diseases of the pericardium). This approach was derived from the Centers for Disease Control and Prevention, and reports that validated strategies for identification of sudden cardiac deaths. ${ }^{24,25}$

Hypoglycemia. Hypoglycemia events were defined as inpatient hospitalizations or emergency department (ED) visits for hypoglycemia, or outpatient blood glucose measurements $<60 \mathrm{mg} / \mathrm{dl}$ (Supplemental Table 1). The ED hypoglycemia algorithm yielded a positive predictive value of $89 \%$ compared with records review in a previous study ${ }^{26}$ For blood glucose values obtained in the outpatient setting, we applied some data quality control measures. We excluded nonnumeric values (such as "high" or "low"), and converted non-absolute values to absolute values so that a glucose value $>400$ would be coded as 400 , and a glucose value $<70$ would be coded as 70. If a patient had hypoglycemia based on the outpatient blood glucose or ED visit which led to a hospitalization within 48 hours, the event was counted as a single event attributed to the hospitalization. Similarly, if a patient had hypoglycemia based on the outpatient blood glucose which led to an emergency visit, the event was considered as a single ED visit.

\section{Secondary Outcomes: Glycated Hemoglobin and Body Mass Index, Chronic Kidney Disease, All-Cause Death \\ Glycated Hemoglobin and Body Mass Index. We compared differences in glycated hemoglobin (HbAlc) levels and body mass index (BMI) between the treatment groups at 12,24, and}


36 months following initiation of insulin. HbA1c and BMI measurements at baseline were collected on the date of insulin initiation or on the closest date within the prior 730 days. Subsequent measurements at 12,24, and 36 months were from each specific month or carried forward from the closest measurement in the prior 730 days. Any implausible values for HbAlc $(<3 \%,>30 \%)$, height ( $<48$ inches, $>90$ inches), and weight $(<50$ pounds, $>700$ pounds) were excluded.

Chronic Kidney Disease. All eGFRs were estimated using the Chronic Kidney Disease Epidemiology Collaboration (CKD-EPI) equation. ${ }^{27}$ Serum creatinine levels $<0.3 \mathrm{mg} / \mathrm{dl}$ were considered implausible and were excluded. eGFR values $\geq 150 \mathrm{ml} / \mathrm{min}$ were truncated at $150 \mathrm{ml} / \mathrm{min}$. NonIDMS (isotope dilution mass spectrometry) calibrated creatinine was adjusted by $5 \% .{ }^{29}$ The composite chronic kidney disease outcome was a sustained $30 \%$ decline in outpatient eGFR measurement or an event indicating end stage renal disease (ESRD) ${ }^{28}$ including dialysis, renal transplant, or reaching eGFR $<15 \mathrm{ml} / \mathrm{min}$ (Supplemental Table 1). All events, except for renal transplant, required a second event that confirmed the decline in eGFR or dialysis event within 3 to 12 months. The date of the confirmatory event was the outcome date.

All-Cause Death. We determined all-cause death using the VHA Vital Status file, which combines information from multiple sources (Medicare, VHA, Social Security and VHA compensation and pension benefits) to determine vital status and date of death. ${ }^{29,30}$ When the VHA date of death conflicted with the NDI date of death $(<3 \%)$, we used the NDI date of death.

\section{Statistical Analyses}

Each outcome was analyzed separately. We evaluated the time to CVD and hypoglycemia (first event following insulin initiation and recurrent events), for insulin alone compared to sulfonylurea + insulin in a propensity score-matched cohort. The propensity score modeled the probability of insulin monotherapy based on multiple baseline characteristics and Veterans Integrated Service Network (VISN) of care (Supplemental Tables 2-3). A 1:1 greedy matching algorithm was used to construct the matched cohort (Supplemental Figure 2; Supplemental Table 3). ${ }^{31,32}$

Cox proportional hazards models were used to compare outcomes for insulin versus sulfonylurea + insulin (reference) in the matched cohort. For recurrent hypoglycemia analyses, robust standard errors were utilized to account for multiple events within individual patients. The fulfillment of the proportional hazards assumptions was verified through examination of log-log survival plots. Secondary outcomes of CKD and death were analyzed using a similar strategy. Wilcoxon rank sum tests were used to compare the median differences in $\mathrm{HbA} 1 \mathrm{c}$ and BMI at 12, 24, and 36 months after intensification between the matched groups.

\section{Subgroup and Sensitivity Analyses}

We assessed for effect modification through stratification by age $(<65$ years and $\geq 65$ years) and baseline eGFR $(<60 \mathrm{ml} /$ $\min$ and $\geq 60 \mathrm{ml} / \mathrm{min}$ ). We also evaluated the significance of corresponding interaction terms, using likelihood ratio tests. As part of sensitivity analyses, we used two alternate definitions for the hypoglycemia outcome; first using only hospitalizations and ED visits, and second using hospitalizations and ED visits for hypoglycemia and outpatient blood glucose $<50 \mathrm{mg} / \mathrm{dL}$. We also examined whether rates of hypoglycemia differed according to the type of sulfonylurea patients were receiving. We compared insulin to glyburide + insulin or glipizide/glimepiride + insulin as the reference group. Analyses were conducted using R (available at: http://www. r-project.org/), Stata 11.1 (StataCorp, College Station, TX), and SAS for Windows 9.2. (SAS Institute, Cary, NC).

\section{RESULTS}

\section{Study Cohort and Patient Characteristics}

We identified 323,857 veterans who initiated diabetes treatment. Of these, $55 \%$ initiated metformin, $43 \%$ sulfonylurea and $2 \%$ other regimens. There were 144,110 patients who initiated sulfonylurea monotherapy. Approximately $49 \%$ never intensified sulfonylurea monotherapy over a median followup of 50 months (interquartile range [IQR] 19, 71). Of 74,115 patients who intensified therapy, we excluded 10,339 patients (14\%) who became non-adherent to sulfonylurea before changing to a different regimen (no sulfonylurea prescriptions filled in the 6 months prior to treatment intensification). We also excluded $3342(5 \%)$ with $<6$ months of follow-up required to define the intensification regimen. Most patients $(\mathrm{N}=53,240[72 \%])$ changed to a non-insulin based-regimen, often switching to or adding metformin. There were 7194 patients who intensified with an insulin regimen. We further excluded 1820 patients ( $25 \%$ ), including those with hospice, dialysis, or transplant codes, missing baseline creatinine, baseline eGFR $<15 \mathrm{ml} / \mathrm{min}$ and data errors (Fig. 1).

Cohort patients were typical of most VHA patients with $98 \%$ being male and $70 \%$ white. Insulin patients and sulfonylurea + insulin patients had similar age, HbA1c, and eGFR at baseline. After propensity score matching, there were 1596 matched patients in each group. Baseline characteristics were similar both before and after propensity score matching (Table 1; Supplemental Table 4). Among those in the matched cohort who used insulin versus sulfonylurea + insulin, $33 \%$ versus $52 \%$ used long-acting; $22 \%$ versus $13 \%$ premixed; $5 \%$ versus $11 \%$ short-acting; and $31 \%$ versus $18 \%$ both long and short-acting insulins. The remaining patients in the matched cohort (9\% insulin and $6 \%$ sulfonylurea + insulin) used other insulin combinations.

The median follow-up before censoring or death was 1.1 years (IQR 0.4, 2.5) among insulin patients and 1.0 year 


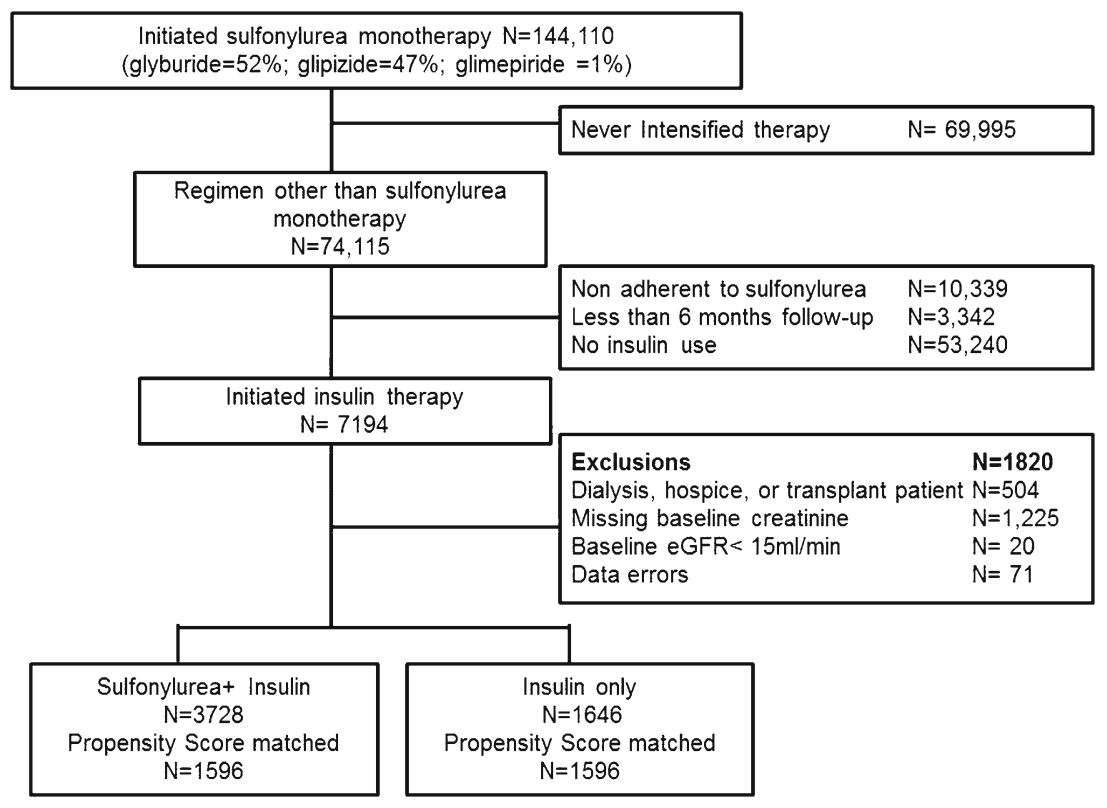

Figure 1. Flow of patients eligible for analyses.

(IQR 0.4, 2.3) among sulfonylurea + insulin patients. Patients were censored for non-persistence on therapy (52\% insulin alone versus $54 \%$ sulfonylurea + insulin), leaving VHA (1\% versus $0.6 \%$ ) or reaching study end (29\% versus $29 \%$ ).

\section{Absolute and Relative Incidence of Fatal and Nonfatal Cardiovascular Events}

There were 128 composite events (54 AMI and stroke hospitalizations, 74 cardiovascular deaths) among 1596 patients on insulin, and 134 events (44 AMI and stroke hospitalizations, 90 cardiovascular deaths) among 1596 patients on sulfonylurea + insulin. Cardiovascular disease (CVD) events per 1000 person-years and $95 \%$ confidence intervals (CIs) were 49.3 $(41.2,58.3)$ and $56.0(47.1,65.9)$, respectively [hazard ratio (HR) $(0.89,95 \%$ CI 0.70, 1.10)] (Table 2).

\section{Absolute and Relative Incidence of Hypoglycemia Events}

There were 179 first hypoglycemia events (47 hospitalizations or ED visits and 132 outpatient glucose $<60 \mathrm{mg} / \mathrm{dL}$ ) among patients on insulin, and 174 events (48 hospitalizations or ED visits and 126 outpatient glucose $<60 \mathrm{mg} / \mathrm{dL}$ ) among patients on sulfonylurea + insulin. The event rates per 1000 personyears and $95 \%$ CIs were $74.0(63.9,85.6)$ and $78.9(68.0$, 91.5), respectively (HR 0.94, $95 \%$ CI 0.76, 1.16) (Table 2). The recurrent event rates per 1000 person-years and $95 \%$ CIs were $100.0(85.1,118.3)$ and $116.8(98.5,139.4)$, respectively (HR 0.87, $95 \%$ CI 0.69, 1.10) (Table 2).

\section{Secondary Outcomes}

Median HbA1c levels decreased after 12 months and were maintained in both groups, but were modestly lower in the insulin monotherapy group with median differences of $-0.2 \%$ and $-0.4 \%$ at 24 and 36 months ( $p=0.003$ and $p<0.001$, respectively) (Fig. 2a). Median BMI increased progressively and similarly in both groups overtime (Fig. 2b).

There were 218 chronic kidney disease (CKD) events among insulin patients (197 with eGFR decline of $>30 \%$ and 21 with ESRD events), and 174 events among matched sulfonylurea + insulin patients (158 eGFR decline of $>30 \%$ and 16 ESRD events). CKD events per 1000 person-years and $95 \%$ CIs were $94.9(83.3,107.7)$ and $78.5(67.7,90.5)$, respectively (HR 1.22, $95 \%$ CI 1.00, 1.49) (Table 2).

There were 285 and 267 deaths among insulin patients and sulfonylurea + insulin patients, respectively. Deaths per 1000 person-years and $95 \%$ CIs were $106.9(95.4,119.2)$ and 108.8 (96.8, 121.8), respectively (HR 0.99, 95 \% CI 0.84, 1.17) (Table 2).

\section{Subgroup and Sensitivity Analyses}

Subgroup analyses stratified by age and eGFR demonstrated results consistent with the primary analysis (Fig. 3; Supplemental Table 5). Furthermore, in models evaluating all-cause death the interaction terms between exposure regimens and age and eGFR were not statistically significant in likelihood ratio tests ( $p=0.301$ and $p=0.433$, respectively). Results from sensitivity analyses with alternate definitions for hypoglycemia were consistent with results from the primary analyses. Similarly, results were consistent when insulin was compared to glyburide + insulin or glipizide/glimepiride + insulin (Supplemental Table 6).

\section{DISCUSSION}

In a large cohort study of predominantly male veterans on sulfonylurea monotherapy, patients who intensified treatment 
Table 1. Baseline Characteristics of Patients in the Propensity Score-Matched Cohort

\begin{tabular}{|c|c|c|c|}
\hline \multirow[b]{2}{*}{ Characteristic } & \multicolumn{3}{|c|}{ Propensity Score Matched Cohort } \\
\hline & $\begin{array}{l}\text { Insulin only } \\
N=1596\end{array}$ & $\begin{array}{l}\text { Sulfonylurea + Insulin } \\
N=1596\end{array}$ & $\mathbf{S D}^{\dagger}$ \\
\hline Age, median (IQR) & $66(58,77)$ & $66(58,77)$ & 0.01 \\
\hline Male $(\%)$ & 98 & 98 & -0.03 \\
\hline \multicolumn{4}{|l|}{ Race, $(\%)^{\dagger}$} \\
\hline White & 70 & 69 & 0.02 \\
\hline Black & 22 & 22 & 0.00 \\
\hline Hispanic/ Other & 6 & 7 & -0.04 \\
\hline Available $\%$ & 97 & 97 & 0.00 \\
\hline Months on sulfonylurea monotherapy, median (IQR) ${ }^{\star, \dagger}$ & $16(7,32)$ & $16(7,30)$ & 0.02 \\
\hline HbAlc, \% & $8.2(6.9,10.1)$ & $8.3(7.0,10.0)$ & -0.01 \\
\hline Available \% & 90.7 & 91.2 & 0.02 \\
\hline Low Density Lipoprotein mg/dL, median (IQR) & $84(65,108)$ & $85(66,107)$ & 0.00 \\
\hline Available \% & 79.6 & 79.6 & 0.00 \\
\hline Glomerular Filtration Rate (ml/min), median (IQR) & $61.1(44,88)$ & $62.2(44,88)$ & -0.02 \\
\hline Creatinine $\mathrm{mg} / \mathrm{dL}$, median (IQR) & $1.24(1.0,1.6)$ & $1.24(1.0,1.6)$ & 0.02 \\
\hline Proteinuria, $(\%)$ & & & 0.06 \\
\hline Negative & 59.8 & 62.5 & \\
\hline Trace through $4+$ & 40.2 & 37.5 & \\
\hline Available $\%$ & 76.9 & 75.7 & -0.03 \\
\hline \multicolumn{4}{|l|}{ Microalbumin to creatinine $\mathrm{mg} / \mathrm{gm},(\%)^{\dagger}$} \\
\hline$<30$ & 15.6 & 17.7 & -0.06 \\
\hline $30-300$ & 8.9 & 8.6 & 0.01 \\
\hline $300+$ & 2.6 & 1.9 & 0.05 \\
\hline Missing & 72.8 & 71.6 & 0.02 \\
\hline Systolic Blood pressure mm/Hg, median (IQR) & $130(118,142)$ & $130(118,143)$ & -0.03 \\
\hline Diastolic Blood pressure mm/Hg, median (IQR) & $72(65,82)$ & $73(64,82)$ & -0.02 \\
\hline Available \% & 98.4 & 98.6 & 0.02 \\
\hline Body Mass Index (kilograms/meter $\left.{ }^{2}\right)$, median $(\mathrm{IQR})^{\dagger}$ & $30.3(26.1,34.6)$ & $30.2(26.4,34.8)$ & -0.02 \\
\hline Available $\%$ & 96.8 & 97.1 & 0.02 \\
\hline \multicolumn{4}{|l|}{ Baseline Comorbidities (\%) } \\
\hline Malignancy & 16 & 16 & -0.01 \\
\hline Liver/ respiratory failure ${ }^{\dagger}$ & 16 & 16 & 0.02 \\
\hline $\mathrm{HIV}^{\dagger}$ & 1 & 1 & 0.00 \\
\hline Congestive heart failure & 29 & 30 & -0.01 \\
\hline Cardiovascular disease & 51 & 51 & 0.00 \\
\hline Serious mental illness & 33 & 33 & 0.01 \\
\hline Smoking & 25 & 24 & 0.03 \\
\hline Obstructive Pulmonary Disease/ Asthma & 28 & 27 & 0.02 \\
\hline Cardiac valve disease & 8 & 8 & 0.01 \\
\hline Arrhythmia & 26 & 26 & 0.01 \\
\hline Parkinson's & 1 & 1 & 0.00 \\
\hline \multicolumn{4}{|l|}{ Use of Medications (\%) } \\
\hline ACE Inhibitors or ARBs & 69 & 69 & 0.00 \\
\hline Anti-hypertensive medications ${ }^{\dagger}$ & 82 & 81 & 0.01 \\
\hline Statin and other lipid lowering agents ${ }^{\dagger}$ & 69 & 68 & 0.01 \\
\hline Anti-arrhythmics, digoxin and inotropes & 4 & 4 & 0.00 \\
\hline Anticoagulants, platelet inhibitors & 24 & 24 & 0.01 \\
\hline Nitrates & 20 & 20 & 0.01 \\
\hline Aspirin & 30 & 31 & -0.02 \\
\hline Loop Diuretics & 37 & 38 & -0.02 \\
\hline Antipsychotics & 11 & 11 & 0.00 \\
\hline \multicolumn{4}{|l|}{ Indicators of health care utilization } \\
\hline Hospitalized in last year $(\%)^{\dagger}$ & 52 & 52 & 0.02 \\
\hline Hospitalized in prior 90 days $(\%)^{\dagger}$ & 36 & 35 & 0.01 \\
\hline Nursing Home encounter $(\%)$ & 0.7 & 0.6 & 0.02 \\
\hline Outpatient Visits, median (IQR) & $9(5,16)$ & $9(5,15)$ & 0.02 \\
\hline Medicare utilization & 47 & 47 & 0.01 \\
\hline Medicaid utilization & 6 & 6 & -0.01 \\
\hline
\end{tabular}

*Abbreviations: IQR median and interquartile range, SD standardized differences, ACE angiotensin converting enzyme, ARB angiotensin receptor blockers

${ }^{+}$Standardized differences (SD) are reported. Standardized differences are the absolute difference in means or percent divided by an evenly weighted pooled standard deviation, or the difference between groups in number of standard deviations. The following $p$ values for sulfonylurea + insulin users versus insulin monotherapy users were statistically significant: race, antihypertensives, HIV, liver and respiratory disease, microalbumin to creatinine ratio at $p<0.05$; months from monotherapy, BMI, lipid lowering medications, and previous hospitalization at $p<0.001$. No $p$ values in propensity score matched cohort were statistically significant

Time to treatment intensification represents the time on sulfonylurea monotherapy, and is an approximation of the duration of diabetes, since patients were free of all hypoglycemic medications for 180 days prior to starting sulfonylurea

by switching to insulin compared with adding insulin had no statistically significant difference in the risk of CVD, hypoglycemia, CKD, or death. However, due to modest size and limited follow-up of our cohort, we could not rule out 
Table 2. Rates and Hazard Ratios (95 \% Confidence Interval [CI]) for Risk of Primary and Secondary Outcomes Among Propensity Score Matched Patients Using Insulin Monotherapy versus Sulfonylurea + Insulin Combination Therapy

\begin{tabular}{|c|c|c|}
\hline Persistent exposure required ${ }^{*}$ & $\begin{array}{l}\begin{array}{l}\text { Insulin only } \\
N=1596\end{array} \\
\text { a }\end{array}$ & $\begin{array}{l}\text { Sulfonylurea + Insulin } \\
N=1596\end{array}$ \\
\hline Composite fatal and nonfatal cardiovascular events & 128 & 134 \\
\hline Person-years & 2597 & 2394 \\
\hline Unadjusted rate/1000 person-years $(95 \% \mathrm{CI})$ & $49.3(41.2,58.3)$ & $56.0(47.1,65.9)$ \\
\hline Hazard ratio ${ }^{\dagger}(95 \%$ CI $)$ & $0.89(0.70,1.10)$ & Reference \\
\hline First hypoglycemia events & 179 & 174 \\
\hline Person-years & 2420 & 2206 \\
\hline Unadjusted rate/1000 person-years & $74.0(63.9,85.6)$ & $78.9(68.0,91.5)$ \\
\hline Hazard ratio ${ }^{\dagger}(95 \%$ CI $)$ & $0.94(0.76,1.16)$ & Reference \\
\hline Recurrent hypoglycemia events & 267 & 287 \\
\hline Person-years & 2669 & 2458 \\
\hline Unadjusted rate/1000 person-years & $100.0(85.1,118.3)$ & $116.8(98.5,139.4)$ \\
\hline Hazard ratio ${ }^{\dagger}(95 \% \mathrm{CI})$ & $0.87(0.69,1.10)$ & Reference \\
\hline Composite chronic kidney disease events & 218 & 174 \\
\hline Person years & 2296.3 & 2216.4 \\
\hline Unadjusted rate/1000 person-years & $94.9(83.3,107.7)$ & $78.5(67.7,90.5)$ \\
\hline Hazard ratio ${ }^{\dagger}(95 \%$ CI $)$ & $1.22(1.00,1.49)$ & Reference \\
\hline All-cause death & 285 & 267 \\
\hline Person years & 2667 & 2453 \\
\hline Unadjusted rate $/ 1000$ person-years & $106.9(95.4,119.2)$ & $108.8(96.8,121.8)$ \\
\hline Hazard ratio ${ }^{\dagger}(95 \% \mathrm{CI})$ & $0.99(0.84,1.17)$ & Reference \\
\hline
\end{tabular}

${ }^{*}$ Primary analysis requires persistence on insulin; patients are censored after 90 days without any insulin available. Patients were followed until each individual outcome and other events were ignored, therefore the amount of person time varies in each analysis

${ }^{\prime}$ Propensity-score matched hazard is derived from Cox proportional hazards model for time to outcome

small to moderate differences in risk. Patients on insulin alone had a modestly greater decrease in HbAlc during follow-up years.

This study compared insulin alone versus sulfonylurea + insulin on both long-term and short-term serious outcomes: CVD and hypoglycemia, respectively. A few previous studies have examined clinical endpoints such as hypoglycemia, $\mathrm{HbAlc}$ and weight gain between these treatments. In a substudy of the U.K. Prospective Diabetes Study (UKPDS), hypoglycemia occurred less frequently with sulfonylurea \pm insulin compared with insulin alone (1.6\% vs. $3.2 \%$ per year, respectively), and a higher proportion of patients achieved HbAlc $<7 \%$ ( $47 \%$ vs. $35 \%$ ). Weight gain over the 6 years of follow-up was similar. ${ }^{33}$ Another large observational study found serious hypoglycemia was more common among those taking sulfonylurea + insulin, compared to either insulin alone or sulfonylurea alone $(3.4 \%, 2.8 \%$, and $1.2 \%$, respective1y). ${ }^{34}$ In a meta-analysis of 17 clinical trials published from 1966 through 1991, a modest improvement in glycemic control and similar weight gain was demonstrated with sulfonylurea + insulin compared to insulin alone. ${ }^{35}$ While these results were contrary to our finding that insulin alone led to lower $\mathrm{HbA1c}$, the between-group differences were very small and likely not clinically different. This may in part be due to the smaller sample size of our groups overtime.

Part of the rationale for the combination of oral hypoglycemic and insulin therapy is that the patient can retain the convenience of oral agents and minimize total exogenous insulin requirements. ${ }^{36}$ Although there is evidence that combination therapy can decrease exogenous insulin requirements, this reduction is small. ${ }^{35}$ In addition, there is little evidence that a modest reduction in insulin use is accompanied by significant differences in weight, hypoglycemia risk, or other long-term clinical benefits such as CVD or CKD prevention. Given our current findings of no large increased risk of clinical outcomes with the use of insulin alone compared with combination of sulfonylurea and insulin, the decision about which regimen to use should be tailored to the individual patient by addressing the potential benefit of using lower insulin dose in combined therapy versus the benefit of regimen simplicity and lower costs (one drug versus two).

Our findings must be interpreted in light of several limitations. Only $5 \%$ of our large inception cohort of sulfonylurea monotherapy users initiated insulin during study follow-up, which limited our sample size and the precision of our estimates. Although large medication effects on the outcomes risks seem unlikely, based on the estimated confidence intervals, more modest effects cannot be ruled out. The hypoglycemia outcome definitions used in our analysis yielded event rates similar to those reported by other groups; however a different definition (either more or less inclusive or serious hypoglycemia) could systematically lead to higher or lower event rates than that which we reported. Importantly, our findings were robust to the use of alternate hypoglycemia definitions. We utilized refill data as a proxy for medication taking, which may result in exposure misclassification, and medication doses were not explored. Nevertheless, prescription fills appear to be a good proxy for medication use. ${ }^{37,38}$ Veterans may not receive all their care or medications in VHA facilities, which could result in missing events or medications. We supplemented our VHA data with Medicare and Medicaid information to reduce the possibility of missing outcomes, and results were similar when stratified by age 65 years and older compared to those less than 65 years of age. We utilized 

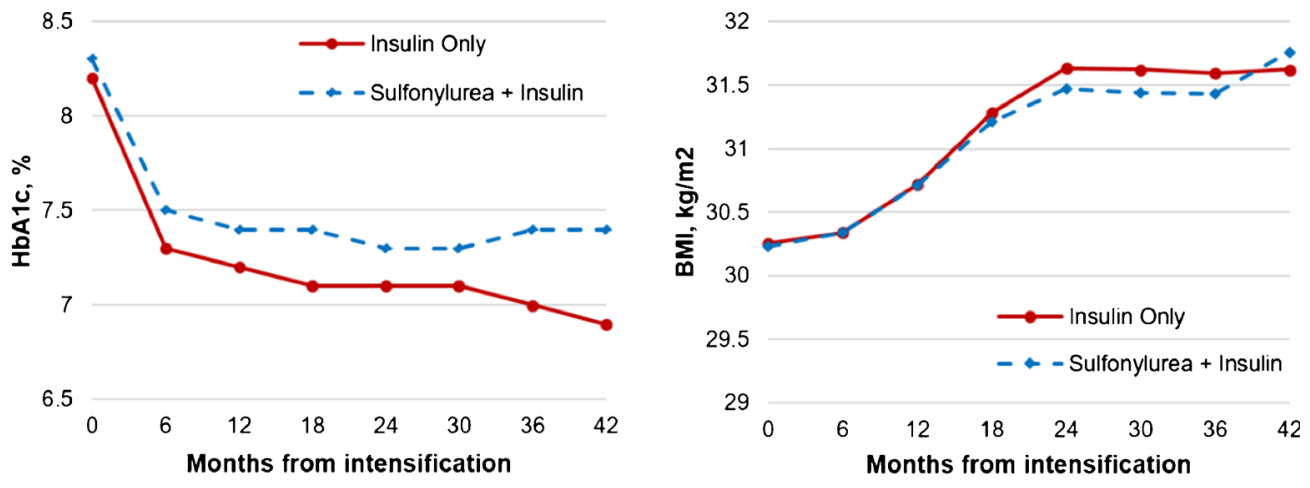

$\begin{array}{lllllllll}\begin{array}{c}\text { Patients receiving } \\ \text { insulin only, } n\end{array} & 1448 & 1148 & 638 & 394 & 1545 & 1162 & 647 \\ \begin{array}{c}\text { Patients receiving } \\ \text { sulfonylurea + }\end{array} & 1456 & 1081 & 594 & 354 & 1550 & 1105 & 607 \\ \begin{array}{c}\text { insulin, } n \\ \text { Median difference }\end{array} & -0.1 & -0.2 & -0.2 & -0.4 & & & \\ \text { P-value }+ & 0.62 & 0.001 & 0.003 & <0.001 & 0.0 & 0.0 & 0.2 \\ \end{array}$

Figure 2. Changes in median HbA1c and BMI after initiating insulin therapy among insulin monotherapy patients and sulfonylurea + insulin combination therapy patients. $\uparrow$ Wilcoxon rank-sum test comparing differences in median HbA1c and BMI.
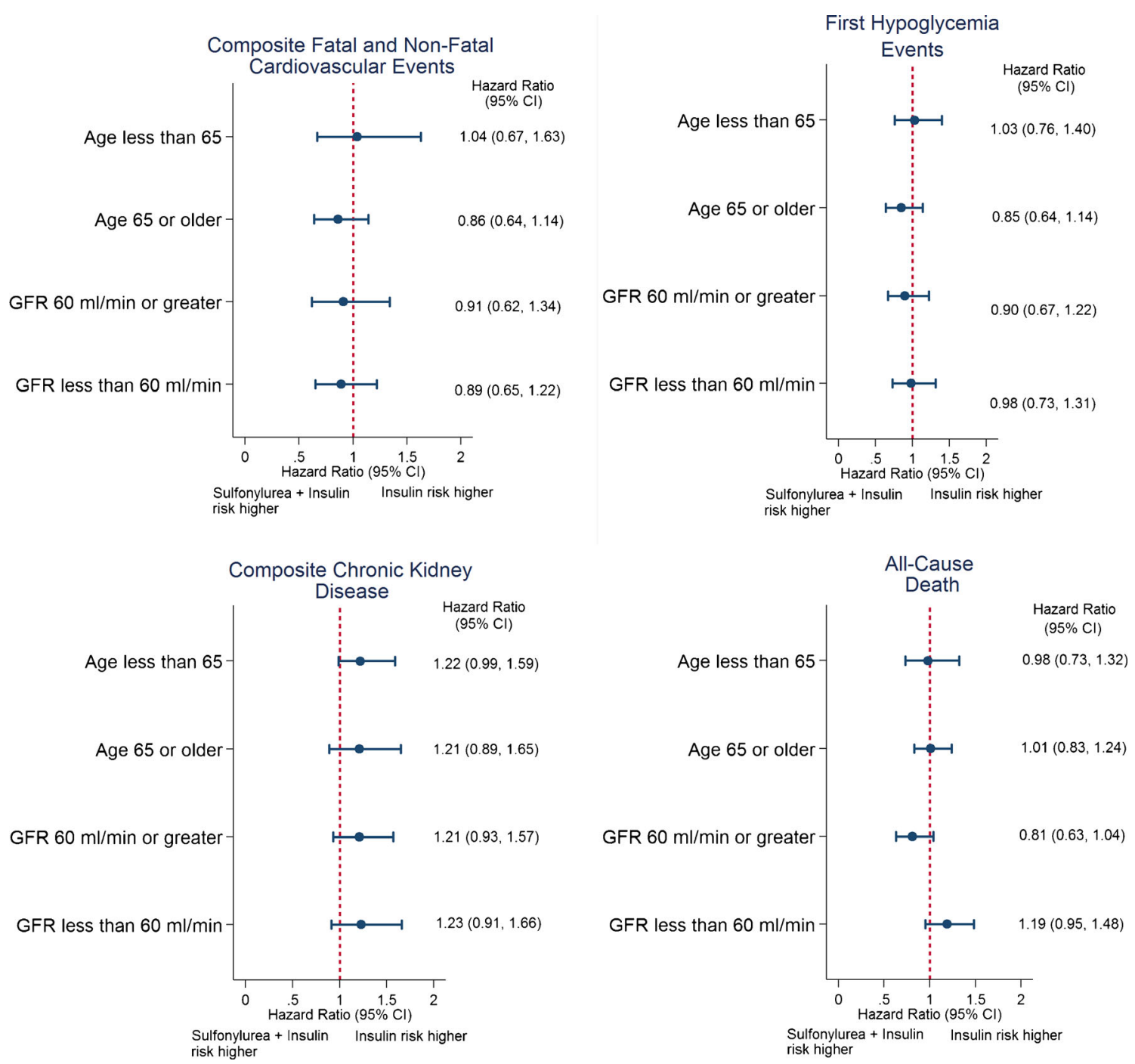

Figure 3. Hazard ratios $(95 \%$ confidence interval $[\mathrm{CI}]$ ) for risk of primary and secondary outcomes among propensity score - matched patients using insulin monotherapy versus sulfonylurea + insulin combination therapy, stratified by age and baseline eGFR subgroups. 
propensity scores and matched on multiple baseline covariates for analysis; however, residual confounding by indication or differences in severity of diabetes remains a possibility. Finally, this study was conducted in veterans, the majority of whom are white men, which must be considered when generalizing our results to other populations.

In conclusion, we found no clinically significant differences in the risk of fatal and non-fatal CVD, hypoglycemia, and other long and short-term outcomes between sulfonylurea initiators who switched to insulin monotherapy and those who added insulin onto sulfonylurea therapy, although modest differences in risk could not be ruled out. Other risks and benefits of each regimen should be discussed with patients to individualize their treatments.

Corresponding Author: Christianne L. Roumie, MD, MPH; Veterans Health Administration - Tennessee Valley Healthcare System Geriatrics Research Education Clinical Center (GRECC), Health Service Research and Development Center (HSRD), Nashville, TN, USA (e-mail: christianne.roumie@vanderbilt.edu).

\section{Compliance with Ethical Standards:}

Disclaimer: The authors of this report are responsible for its content. Statements in the report should not be construed as endorsement by the Agency for Healthcare Research and Quality, the U.S. Department of Health and Human Services, or the Department of Veterans Affairs.

Funding: This project was funded by the Agency for Healthcare Research and Quality, US Department of Health and Human Services, Contract No. HHSA2902010000161, as part of the Developing Evidence to Inform Decisions about Effectiveness (DEcIDE 2) program. This work was supported in part by VA CSRD investigator initiated grant I01CX000570-01 (Roumie), Clinical and Translational Science Award (CTSA) No. TL1TR000447-08 from the NCATS (Min), the Center for Diabetes Translation Research P30DK092986 (Elasy, Roumie) and VA Career Development Award 2-031-09S (Hung). Support for Veterans Affairs/Centers for Medicare \& Medicaid Services data provided by the Department of Veterans Affairs, Veterans Affairs Health Services Research and Development Service, Veterans Affairs Information Resource Center (project numbers SDR 02-237 and 98-004).

Prior Presentations: Parts of this study were presented as abstracts at the Translational Science Meeting, Washington DC, 15-18 April 2015 and at the International Conference on Pharmacoepidemiology and Therapeutic Risk Management, Boston, MA, 22-26 August 2015.

Conflicts of Interest: The authors have no conflicts of interest to declare.

\section{REFERENCES}

1. Inzucchi SE, Bergenstall RM, Buse JB, Diamant M, Ferrannini E, Nauck M, Peters AL, Tsapas A, Wender R, Matthews DR. Management of hyperglycemia in type 2 diabetes, 2015: a patient-centered approach: update to a position statement of the American Diabetes Association and the European Association for the Study of Diabetes. Diabetes Care. 2015;38:140-149.

2. Glucophage final printed labeling 2001.

3. Inzucchi SE, Lipska KJ, Mayo H, Bailey CJ, McGuire DK. Metformin in patients with type 2 diabetes and kidney disease: a systematic review. JAMA. 2014;312:2668-2675

4. Abrahamson MJ. Should sulfonylureas remain an acceptable first-line add-on to metformin therapy in patients with type 2 diabetes? Yes, they continue to serve us well! Diabetes Care. 2015;38:166-169.
5. National Kidney Foundation. KDOQI clinical practice guideline for diabetes and CKD: 2012 update. Am J Kidney Dis. 2012;60:850-886.

6. Genuth S. Should sulfonyolureas remain an acceptable first-line add-on to metformin therapy in patients with type 2 diabetes? No, it's time to move on! Diabetes Care. 2015;38:170-175.

7. Inzucchi SE, Bergenstall RM, Buse JB, Diamant M, Ferrannini E, Nauck M, Peters AL, Tsapas A, Wender R, Matthews DR. Management of hyperglycemia in type 2 diabetes: a patient-centered approach: Position statement of the American Diabetes Association (ADA) and the European Association for the Study of Diabetes (EASD). Diabetes Care. 2012;35:1364-1379.

8. Feil DG, Rajan M, Soroka O, Tseng CL, Miller DR, Pogach LM. Risk of hypoglycemia in older veterans with dementia and cognitive impairment: implications for practice and policy. J Am Geriatr Soc. 2011;59:22632272.

9. Libby AM, Pace W, Bryan C, Anderson HO, Ellis SL, Allen RR, Brandt E, Huebschmann AG, West D, Valuck RJ. Comparative effectiveness research in DARTNet primary care practices: point of care data collection on hypoglycemia and over-the-counter and herbal use among patients diagnosed with diabetes. Med Care. 2010;48:S39-44.

10. Stoekenbroek RM, Rensing KL, Bernelot Moens SJ, Nieuwdorp M, DeVries JH, Zwinderman AH, Stroes ES, Currie CJ, Hutten BA. High daily insulin exposure in patients with type 2 diabetes is associated with increased risk of cardiovascular events. Atherosclerosis. 2015;240:318-323.

11. Rensing KL, Reuwer AQ, Arsenault BJ, von der Thusen JH, Hoekstra JBL, Kastelein JJP, Twickler TB. Reducing cardiovascular disease risk in patients with type 2 diabetes and concomitant macrovascular disease: can insulin be too much of a good thing? Diabetes Obes Metab. 2011;13:10731087 .

12. Roumie CL, Greevy RA, Grijalva CG, Hung AM, Liu X, Murff HJ, Elasy TA, Griffin MR. Association between intensification of metformin treatment with insulin vs sulfonylureas and cardiovascular events and all-cause mortality among patients with diabetes. JAMA. 2014;311:2288-2296.

13. Schramm TK, Gislason GH, Vaag A, Rasmussen JN, Folke F, Hansen ML, Føsbol EL, Køber L, Norgaard ML, Madsen M, Hansen PR, TorpPedersen C. Mortality and cardiovascular risk associated with different insulin secretagogues compared with metformin in type 2 diabetes, with or without a previous myocardial infarction: a nationwide study. Eur Heart J. 2011;32:1900-1908.

14. Williams SA, Shi L, Brenneman SK, et al. The burden of hypoglycemia on healthcare utilization, costs, and quality of life among type 2 diabetes mellitus patients. J Diabetes Complicat. 2012;26:399-406.

15. Johnston SS, Smith DM, Conner C, et al. Evidence linking hypoglycemic events to an increased risk of acute cardiovascular events in patients with type 2 diabetes. Diabetes Care. 2011;34:1164-70.

16. Bonds DE, Miller ME, Bergenstal RM. The association between symptomatic, severe hypoglycaemia and mortality in type 2 diabetes: retrospective epidemiological analysis of the ACCORD study. BMJ. 2010;340:b4909.

17. Arnold N, Hines D, Stroupe K. Comparison of VA Outpatient Prescriptions in the DSS Datasets and the PBM Database. In: Center VIR, ed. VIREC Technical Report \# 1. Hines, IL: Edward Hines, Jr. VA Hospital; 2006.

18. International Classification of Diseases, Ninth Revision, Clinical Modification. Washington, DC: Public Health Service, US Dept of Health and Human Services; 1988.

19. Humensky J, Carretta H, de Groot K, Brown MM, Tarlov E, Hynes D. Service Utilization of Veterans Dually Eligible for VA and Medicare Fee-ForService: 1999-2004. Medicare \& Medicaid Research Review 2012;2.

20. Hynes DM, Koelling $\mathbf{K}$, Stroupe $\mathbf{K}$. Veterans' access to and use of Medicare and Veterans Affairs health care. Med Care. 2007;45:214-23.

21. McCarthy JF, Valenstein M, Kim HM, Igen M, Zivin K, Blow FC. Suicide mortality among patients receiving care in the veterans health administration health system. Am J Epidemiol. 2009; 169:1033-1038.

22. Greevy RA Jr, Huizinga MM, Roumie CL. Comparisons of persistence and durability among three oral antidiabetic therapies using electronic prescription-fill data: the impact of adherence requirements and stockpiling. Clin Pharmacol Ther. 2011;90:813-9.

23. Niesner K, Murff HJ, Griffin MR, Wasserman B, Greevy RA, Grijalva CG, Roumie CL. Validation of VA administration data algorithms for identifying cardiovascular disease hospitalization. Epidemiology. 2013;24:334-335.

24. Chung CP, Murray KT, Stein CM, Hall K, Ray WA. A computer case definition for sudden cardiac death. Pharmacoepidmiol Drug Saf. 2010; 19:563-572.

25. Ray WA, Meredith S, Thapa PB, Meador KG, Hall K, Murray KT. Antipsychotics and the risk of sudden cardiac death. Arch Gen Psychiatry. 2001;58:1161-1167. 
26. Ginde AA, Blanc PG, Lieberman RM. Validation of ICD-9-coding algorithm for improved identification of hypoglycemia visits. BMC Endocr Disord. 2008;8:4.

27. Matsushita K, Mahmoodi BK, Woodward M, Emberson JR, Jafar TH, Jee SH, Polkinghorne KR, Shankar A, Smith DH, Tonelli M, Warnock DG, Wen CP, Coresh J, Gansevoort RT, Hemmelgarn BR, Levey AS. Comparison of risk prediction using the CKD-EPI equation and the MDRD study equation for estimated glomerular filtration rate. JAMA. 2012;307:1941-1951

28. Coresh J, Turin TC, Matsushita K, Sang Y, Ballew SH, Appel LJ, Arima H, Chadban SJ, Cirillo M, Djurdjev O, Green JA, Heine GH, Inker LA, Irie F, Ishani A, Ix JH, Kovesdy CP, Marks A, Ohkubo T, Shalev V, Shankar A, Wen CP, de Jong PE, Iseki K, Stengel B, Gansevoort RT, Levey AS. Decline in estimated glomerular filtration rate and subsequent risk of end-stage renal disease and mortality. JAMA. 2014;311:2518-2531.

29. Arnold N, Sohn M, Maynard C, DM H. VIREC technical report 2: VA NDI mortality data merge project, 2006.

30. Sohn MW, Arnold N, Maynard C, Hynes DM. Accuracy and completeness of mortality data in the department of veterans affairs. Popul Health Metrics. 2006;4:2.

31. Parsons L. Reducing bias in a propensity score matched-pair sample using greedy matching techniques. In SAS SUGI 26, Paper; 2001:214-26.
32. D'Agostino R, Rubin D. Estimating and using propensity scores with partially missing data. J Am Stat Assoc. 2000;95:749-759.

33. Wright A, Burden AC, Paisey RB, Cull CA, Holman RR. Sulfonylurea inadequacy: efficacy of addition of insulin over 6 years in patients with type 2 diabetes in the U.K. Prospective diabetes study (UKPDS 57). Diabetes Care. 2002;25:330-336.

34. Shorr RI, Ray WA, Daugherty JR, Griffin MR. Incidence and risk factors for serious hypoglycemia in older persons using insulin or sulfonylureas. Arch Intern Med. 1997; 157:1681-1686.

35. Pugh JA, Wagner ML, Sawyer J, Ramirez G, Tuley M, Friedberg SJ. Is combination sulfonylurea and insulin therapy useful in niddm patients? A metaanalysis. Diabetes Care. 1992;15:953-959.

36. Alvarsson M, Sundkvist G, Lager I, Berntorp K, Fernqvist-Forbes E, Steen L, Orn T, Holberg MA, Kirksaether N, Grill V. Effects of insulin vs. Glibenclamide in recently diagnosed patients with type 2 diabetes: a 4-year follow-up. Diabetes Obes Metab. 2008;10:421-429.

37. Grymonpre R, Cheang M, Fraser M, Metge C, Sitar DS. Validity of a prescription claims database to estimate medication adherence in older persons. Med Care. 2006;44:471-477.

38. Metge C, Grymonpre R, Dahl M, Yogendran M. Pharmaceutical use among older adults: using administrative data to examine medicationrelated issues. Can $\mathrm{J}$ Aging (La revue Canadienne du vieillissement). 2005;24(Suppl 1):81-95. 